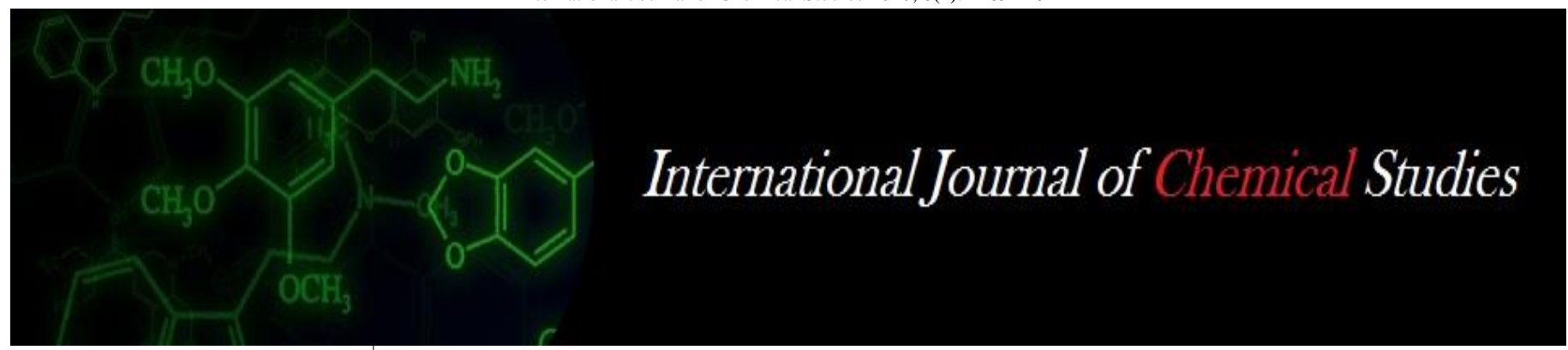

P-ISSN: 2349-8528

E-ISSN: 2321-4902

IJCS 2020; 8(1): 1289-1292

(C) 2020 IJCS

Received: 16-11-2019

Accepted: 18-12-2019

Shweta Kumari

M.Sc. (Ag.) Student,

Department of Extension

Education, Dr. Rajendra Prasad

Central Agricultural University,

Pusa, Samastipur, Bihar, India

Satya Prakash

Assistant Professor Cum-

Scientist, Department of

Extension Education,

Dr. Rajendra Prasad Central

Agricultural University, Pusa,

Samastipur, Bihar, India

\section{Study on adoption of cimate-smart system of wheat intensification (SWI) technology among the farmers of Bihar}

\author{
Shweta Kumari and Satya Prakash
}

DOI: https://doi.org/10.22271/chemi.2020.v8.i1r.8434

\begin{abstract}
Wheat (Triticum aestivum L.) is world's most widely cultivated food crop. At initial decades of 21 st century, one probability of a great famine appeared in the world due to long drought in tropics and subtropics and at the same time it appeared more dangerously because of the climate change threat. System of Wheat Intensification (SWI) which is based on the principles of System of Rice Intensification (SRI) is a new wheat cultivation technique which might act as a significantly new weapon as a part of climate-smart farming. It is one of the promising technologies to increase productivity which ultimately contributes to the household level food security of rural marginal farmers. The present study was conducted in Samastipur district of Bihar state in India. 4 panchayats (Thahara, Morsand, Indarwara, Sarangpur) were selected from 2 blocks of Samastipur based on assumption that these blocks have the largest number of adopters of SWI technology. The total number of respondents (beneficiaries and nonbeneficiaries) selected for the study was 60 . Frequency, percentage, arithmetic mean, standard deviation and t-test were used as the statistical tools. As the result, it was found that majority of the adopters (50\%) had medium level of adoption followed by high level of adoption (40\%) whereas; majority of the nonadopters $(60 \%)$ had low level of adoption. The adopters have significantly higher mean adoption scores (46.96) than that of non-adopters (29.73). The computed t-value (13.61) was found to be highly significant which referred a significant difference in the mean adoption scores of adopters and nonadopters. Moreover, it was discerned that maximum number of respondents in partial adoption was due to lack of information source $(80 \%)$ and maximum number of respondents in non-adoption was due to non-availability of labourers as well as lack of delivery system at village level (100\%).
\end{abstract}

Keywords: SWI, climate change, climate-smart farming, adoption, non-adoption, partial adoption

\section{Introduction}

Wheat is one of the leading food crops of the world farming and occupies significant position among the cultivated cereals. Cultivation of wheat has been the symbolic of green revolution that played pivotal role in making the nation India a food surplus nation. Presently wheat is grown in about 29.25 million hectare area with a production and productivity of 99.70 million tonnes and 3.1tonnes per hectare respectively and it contributes nearly 35 per cent to the national food basket. Introduction of semi dwarf varieties increased the consumption of fertilizer per unit area tremendously and promoted mechanization in agriculture. In one side it increased the overall production and postponed the near seen dangerous cloud of the great famine due to population explosion in the third world where there was very low growth rate of crop production as compared to population growth. However in long term advantages of green revolution were taken only by developed country and farmers who were fortified by irrigation, mechanization and high agro inputs. But at initial decades of 21 st century another probability of great famine appeared in the world due to long drought in tropical and subtropical and at the same time it appeared more dangerously because most of the developed countries adopted policies of using consumable grains into bio fuel production. Therefore, another very serious initiative was needed to increase the productivity of major crop in the very marginal land with low input and sustainable way. In this context, in many parts of the third world System of Wheat Intensification created government attention. Among winter crops, it contributes nearly about 49 per cent of food grains. In Bihar, wheat is grown about 2.1 million hectare with a production and productivity of 4 million tonnes and 1.95 tonnes per hectare, respectively.
Corresponding Author: Shweta Kumari

M.Sc. (Ag.) Student,

Department of Extension Education, Dr. Rajendra Prasad Central Agricultural University, Pusa, Samastipur, Bihar, India 
Wheat has been the staple food of the majority of population of Bihar. It forms the very basis of foods security system of our state. Wheat production of our state has maintained an uprising trend despite of various unpredictable situations of weather uncertainties. In spite all of these achievements, the productivity picture of wheat in Bihar $(24 \mathrm{q} / \mathrm{ha})$ is not very encouraging, rather quite low when compared with national wheat productivity $(31.4 \mathrm{q} / \mathrm{ha})$. In Bihar rice-wheat culture is practiced in $80 \%$ of arable land area. A growing movement has emerged during the past few decades to question the role of the agricultural establishment in promotion practices that contribute to the social problems. Innovative agricultural practices not only address many environmental and social concerns, but also offer economically viable opportunities for growers, labourers, consumers, policy makers and many others in the entire food production system.

Therefore, there is a need for adoption of intensive agricultural practices for increasing the productivity in wheat to ensure food security for the people. System of wheat intensification (SWI) is an adoption of technique used in the system of rice intensification (SRI) methodology of increasing the productivity of crops by changing the management of plant, soil, water and nutrients while reducing external inputs use. Fortunately, experience with the system of rice intensification developed in Madagascar over 30 years ago by father Hendrei de Laulani'e offers some ways to make production system, cost effective, efficient and of increase climate secure. The merit of system have now been demonstrated worldwide especially rice growing countries of Asia and many other countries as well as its concept and practices are now being extended beyond irrigated rice to wheat, ragi, sugarcane, beans and other crops (Thapa et al., 2011).

System of wheat intensification has been tested as an innovative approach to increase productivity and being practiced in India, China, Ethiopia, Poland and USA. SRI has already been tested and evaluated by several NGOs, but System of wheat intensification is still a new technology for wheat cultivation in India. The main objective of this trail is to compare the yield from traditional practice with that from SWI. Results has sown that grain yield of wheat is increased by $91 \%$ at its maximum, with adoption of this technology (Khadka et al., 2011).

The prevalent system of wheat cultivation requires more chemical fertilizers and nearly $120-180 \mathrm{~kg}$ of seed per hectare. SWI use only 20-30 kg improved seed per hectare. $15-20 \mathrm{~cm}$ spacing between row to row and plant to plant, use of manure and organic seed treatment ensure higher yield. Sufficient spacing between the plants and sowing of two seed grains at one point facilitates desired moisture, aeration, nutrition and light to the crop roots. This helps faster growth of plants. Only 2-3 times irrigation and weeding through cono-weeder save times and expenses on labour. SWI is primarily based on these two principles of crop production first principle of root development and second principle of intensive care. System of wheat intensification (SWI) is one of the promising technologies to increase productivity which ultimately contributes to the household level food security of marginal farmers. It might act as a significant new technology towards the domain of climate-smart agriculture

\section{Objectives of the study}

The main objective of study is to measure the extent of adoption of SWI by the farmers of Samastipur district of Bihar state in India. The specific objectives are to:

- Assess the extent of adoption of SWI method of wheat cultivation among the adopters as well as non-adopters.

- Examining the difference in the adoption level of adopters and non-adopters towards SWI technology.

- Divulging the prominent reasons behind partial adoption and non-adoption of SWI technology.

\section{Methodology}

The study was conducted in Samastipur district of Bihar state. Samastipur district was selected purposively because the researcher's university/institute is located exactly here and thus it would be easily approachable. Moreover, the researcher is well acquainted with the culture, social customs and situations prevailed in this district. 2 specific blocks viz. Pusa and Morwa blocks have been selected for the study purpose based on assumption that the block has the largest number of adopters of SWI technology. 2 Panchayats viz. Thahara and Morsand were selected among 13 Panchayats of Pusa block and 2 Panchayats viz. Indarwara and Sarangpur were selected among 18 Panchayats of Morwa block. A complete list of the adopters who have undergone through cultivation of wheat through SWI technology was obtained from District Agricultural Officer Samastipur. 15 adopters and 15 non-adopters respondents from each of 2 blocks were purposively selected. Therefore 30 beneficiary and 30 nonbeneficiary respondents were selected. So, the total number of beneficiaries and non-beneficiaries selected for the study was 60.

Table 1: Selection of the respondents

\begin{tabular}{|c|c|c|c|c|c|}
\hline Sl. No. & Name of the block & Name of the selected villages & Total number of the respondents & Selected adopters & Selected non-adopters \\
\hline \multirow{2}{*}{1.} & \multirow{2}{*}{ Pusa } & Thahara & 15 & 8 & 7 \\
\cline { 3 - 6 } & \multirow{2}{*}{2.} & Morwand & 15 & 7 & 8 \\
\cline { 3 - 6 } & \multirow{2}{*}{ Morwa } & Indrawara & 15 & 7 & 8 \\
\cline { 3 - 6 } & Sarangpur & 15 & 8 & 7 \\
\hline
\end{tabular}

Only the primary data is used and that was collected through survey. Data has been collected through preparation of wellstructured interview schedule. The level/extent of adoption was measured in terms of full adoption, partial adoption and non-adoption of recommended wheat growers. For full adoption of technology a score of 3 , for partial adoption a score 2 was assigned and for non-adoption of recommended technology a 1 score was given. Individual score was later converted to standardize score of adoption index with help of the following formula. Adoption index $=$ (obtained score/ highest obtainable score) x 100. The level of adoption of the respondents was further categorized as high, medium and low by working out arithmetic mean and standard deviation (S.D). If the obtained score is below (Mean-S.D), that respondent is placed in low category. If the score is between (Mean-S.D.) to (Mean+S.D.), that respondent is placed in medium category and if the score is above (Mean+S.D.), the respondent is placed in high category. 't'-test was done to measure the difference between the level of adoption of adopters and nonadopters. Frequency and percentage was used to divulge the 
most notable reasons behind partial adoption and nonadoption.

\section{Results and Discussion}

Level/Extent of adoption of both adopter and non-adopter respondents

To assess the extent of adoption on SWI technology, an adoption test was specially developed for the purpose, which constituted of 22 questions with full adoption getting a score 3 , partial adoption getting a score 2 and non-adoption getting a score 1. The test was administered to both the samples of respondents the adopters and non adopters. By using the adoption index formula, the adoption score of all the 30 adopters and 30 non-adopters were put in a statistical process to find out the arithmetic mean and standard deviation, which eventually were used to estimate frequency and percentages.

Table 2: Frequency and percentage distribution of adopters and non-adopters with respect to their extent of adoption

\begin{tabular}{|c|c|c|c|c|c|}
\hline \multirow{2}{*}{ Sl. No. } & \multirow{2}{*}{ Category } & \multicolumn{2}{|c|}{ Adopters $(\mathbf{n = 3 0})$} & \multicolumn{2}{c|}{ Non-adopters $(\mathbf{n}=30)$} \\
\cline { 3 - 6 } & & Frequency & Percentage & Frequency & Percentage \\
\hline 1. & Low & 3 & 10 & 18 & 60 \\
\hline 2. & Medium & 15 & 50 & 9 & 30 \\
\hline 3. & High & 12 & 40 & 3 & 10 \\
\hline & Total & 30 & 100 & 30 & 100 \\
\hline
\end{tabular}

As the result in the table revealed, majority of Adopters had medium level of adoption i.e. 50 percent followed by high level which is 40 percent. Whereas, in case of non-adopters majority had low level of adoption which is 60 percent followed by medium level of adoption which is 30 percent and only 10 percent had high level of adoption.

The difference in the adoption level of adopters and nonadopters towards SWI technology

Table 3: Differences in the adoption level towards SWI technology of adopters and non-adopters

\begin{tabular}{|c|c|c|c|c|c|c|}
\hline \multirow{2}{*}{ Sl. No. } & \multirow{2}{*}{ Characteristics } & \multicolumn{2}{|c|}{ Mean adoption score of respondents } & \multicolumn{2}{c|}{ S.D. of the respondents } & \multirow{2}{*}{ t-value } \\
\cline { 3 - 6 } & & Adopters(30) & Non-adopters(30) & Adopters(30) & Non-adopters(30) & 4.28 \\
\hline 1. & Level of adoption of SWI technology & 46.96 & 29.93 & 5.45 & $13.61 * *$ \\
\hline
\end{tabular}

**Significant at 1 percent level of significance

Table -3 revealed that the difference is the mean adoption score of adopters and non-adopters were tested for its statistical significance by calculating the t-value. The computed value of ' $t$ ' (13.61) was found to be highly significant at 1 percent level of significance which indicated that there was significant difference in the mean adoption scores of adopters and non-adopters. As the adopters have significantly higher mean adoption scores (46.96) than that of the non-adopters (29.73), it can be concluded that the beneficiaries had higher adoption level than the nonbeneficiaries.

Prominent reasons behind partial adoption and nonadoption of SWI technology

Partial adoption is defined as the adopters who adopt new technology or innovative ideas at initial stage but leave it duet some reasons, might be due to less yield, higher cost of input, non availability of labourers, more labour cost etc.

Table 4: Reasons behind the partial adoption of SWI technology

\begin{tabular}{|c|c|c|c|}
\hline Sl. No. & Constraints faced by partial adopters & Frequency & Percentage \\
\hline 1. & Non availability of labourers & 20 & 66.66 \\
\hline 2. & High cost of labourers & 18 & 60 \\
\hline 3. & Lack of information sources & 24 & 80 \\
\hline 4. & Lack of delivery system at village level & 21 & 70 \\
\hline 5. & Adulteration of inputs & 18 & 60 \\
\hline 6. & Non availability of power machine & 20 & 66.66 \\
\hline 7. & Lack of information & 9 & 30 \\
\hline 8. & Lack of irrigation facility & 17 & 56.66 \\
\hline 9. & Lack of fund & 21 & 70 \\
\hline 10. & High rental charge of machinery & 16 & 53.34 \\
\hline
\end{tabular}

Table 4 shows that maximum number of respondents in partial adoption category were due to lack of information sources i.e. 80 percent followed by lack of fund and lack of delivery system at village level i.e. 70 percent, followed by non availability of labourer i.e. 66.66 percent.

Table 5: Reasons behind the partial non adoption of SWI technology

\begin{tabular}{|c|c|c|c|}
\hline Sl. No. & Constraints faced by partial adopters & Frequency & Percentage \\
\hline 1. & Non availability of labourers & 30 & 100 \\
\hline 2. & High cost of labourers & 27 & 90 \\
\hline 3. & Lack of information sources & 24 & 80 \\
\hline 4. & Lack of delivery system at village level & 30 & 100 \\
\hline 5. & Adulteration of inputs & 16 & 53.34 \\
\hline 6. & Non availability of power machine & 21 & 70 \\
\hline 7. & Lack of information & 12 & 40 \\
\hline
\end{tabular}




\begin{tabular}{|c|c|c|c|}
\hline 8. & Lack of irrigation facility & 15 & 50 \\
\hline 9. & Lack of fund & 18 & 60 \\
\hline 10. & High rental charge of machinery & 17 & 56.67 \\
\hline
\end{tabular}

Table 5 shows that maximum number of respondents in nonadopter category was due to lack of labourers and lack of delivery system at village level i.e. 100 percent followed by labour cost i.e. 90 percent, followed by lack of information sources i.e. 80 percent

\section{Conclusion and Recommendations}

The social science research leading to degree has its own limitation in terms of time and resources. This study also fall in the category of social sciences faced a lot of constraints in generalizing the findings beyond the purview of the research areas. However, what emerged out of this study that its findings may be taken as appoint of reference to start of drive for improving the extent of adoption especially in those component where a lot a ground still seems to be covered.

There were several constraints in adopting SWI technology but adopters were able to remove these constraints successfully as they learned various technical knowhow during the training programme, whereas non-adopters felt more constraint as they lack that particular knowhow. Major constraint for partial and non-adopters were non availability of labourers. The sharpness and productivity of finding depends on selective use of variables responsible for affecting the extent of adoption. The variables which were found accountable for adoption of System of Wheat Intensification (SWI) should be profitable manipulated. Some of the variables which were found within manageable range of the farmers and some are to be induced by change promoters. There should be concerted drive to induce sense of unique venture in farmers through motivational drives. Though, the findings have revealed the adoption level of various components of System of Wheat Intensification is needed, however, to conduct study for building the theoretical base for future research:

1. Identifying suitable varieties and location for adoption of SWI.

2. Focussed activities to mitigate the effects of climate change through SWI adoption.

3. Refinement of machinery for weeding.

4. Promotion of community based nurseries.

5. Organizing training programmes for the trainers, farmers and farm labourers.

6. Involving the NGO's in promotional activities for adoption of SWI.

7. Bringing together the water user association and the irrigation department officials.

8. Give financial support to research on improving management practices, tools and economic evaluation at farm level.

9. Promote direct seeding with a drum seeder and machine planting (with suitable modifications) where labour scarcity limits SWI adoption.

10. Provide farmers with subsidies for adopting SWI and incentives for saving water.

\section{References}

1. Kuwar. Adoption of mushroom cultivation by rural women of Kanpur, Uttar Pradesh: Problems and Perspectives. Progressive Agriculture. 2002; 2(1):31-33.
2. Laguna RJP. System of Rice intensification with less input Indian Journal of Agricultural Economics. 2002; 60(3):458-472.

3. Relker PM, DGM (Tech.), TDS and HO. System of wheat intensification (SWI). Technical Digest, issue 13, Jan, 2011.

4. Sridevi V, Chellamuthu V. Influence of System of Rice Intensification on growth, yield and nutrient uptake of rice. Madras Agric. J. 2012; 99(4-6):305-307. 